\title{
Gênese e Formação Socioespacial da Região do Vale do Itajaí, SC, Brasil: projeto Acolhida na Colônia
}

\author{
Elisângela da Silva Rocha ${ }^{a}$ \\ Luiz Carlos da Silva Flores ${ }^{b}$ \\ Raquel Maria Fontes do Amaral Pereirac
}

\section{Resumo}

O projeto Acolhida na Colônia é uma forma de turismo rural em que as famílias de agricultores imigrantes europeus recebem os turistas em suas propriedades e apresentam seu modo de viver junto à natureza. Esta pesquisa objetiva discutir a gênese e os aspectos socioespaciais do Alto Vale do Itajaí e, mais especificamente, dos municípios que compõem o projeto Acolhida na Colônia, visando a compreender os aspectos que antecederam o momento atual e contribuíram para a inserção das cidades no projeto. Para atingir o objetivo proposto, optou-se pela adoção de um estudo de caso com pesquisa descritiva e bibliográfica de caráter exploratório a fim de contextualizar a formação socioespacial do local estudado. Os resultados demonstram que o contexto socioespacial da região investigada contribui de forma significativa para a expansão e reconfiguração da atividade turística e, por consequência, contribui também para o desenvolvimento regional.

Palavras-chave: Aspectos socioespaciais; Alto Vale do Itajaí; Acolhida na Colônia.

\section{Abstract \\ Origin and Socio-spatial Formation of the Alto Vale do Itajaí Region, SC, Brazil: the Acolhida na Colônia Project}

The Acolhida na Colônia project can be classified as a type of rural tourism in which families of European descent host tourists on their farms and show their way of living close to nature. The present study aimed at discussing the origin and socio-spatial aspects of the Alto Vale do Itajaí region and the municipalities that are part of the Acolhida na Colonia project. The goal was to understand the aspects that preceded the current moment and led those cities to be included in the project. In order to achieve the aim, we adopted a case study with descriptive and bibliographical research of an exploratory quality. Thus, it was possible to contextualize the socio-spatial formation of the study site. Results indicated that the socio-spatial context of that region contributes significantly to the expansion and reconfiguration of tourism activity and, consequently, to regional development.

Keywords: Socio-spatial aspects; Alto Vale do Itajaí; Acolhida na Colônia.

a. Doutoranda em Turismo e Hotelaria pela Universidade do Vale do Itajaí (Univali). Atualmente é professora de Administração/Gestão do Ensino Básico, Técnico e Tecnológico do Instituto Federal Catarinense Campus Camboriú. Itajaí, Santa Catarina, Brasil. E-mail: elisangeladsr@hotmail.com

b. Doutor em Engenharia de Produção. Docente do Mestrado e Doutorado em Turismo e Hotelaria da Univali. Itajaí, Santa Catarina, Brasil. E-mail: flores@univali.br

c. Doutora em Geografia Humana. Docente e Pesquisadora do Mestrado e Doutorado em Turismo e Hotelaria da Univali/Pesquisadora de Produtividade em Pesquisa do CNPq. Itajaí, Santa Catarina, Brasil. E-mail: raquelfontes@univali.br 


\section{Resumen}

Génesis y formación socioespacial de la región del Alto Vale do Itajaí, SC, Brasil: proyecto Acolhida na Colônia

El proyecto Acolhida na Colônia es una forma de turismo rural en que las familias de agricultores inmigrantes europeos reciben turistas en sus propiedades y les presentan su manera de vivir junto a la naturaleza. Esta investigación pretende analizar la génesis y los aspectos socioespaciales del Alto Vale do Itajaí y, más concretamente, de los municipios que forman parte del proyecto Acolhida na Colônia, buscando comprender los aspectos que precedieron el momento actual y contribuyeron a la integración de estos municipios en el proyecto. Para lograr el objetivo propuesto, optamos por la adopción de un estudio de caso con investigación descriptiva y bibliográfica de carácter exploratorio con el fin de contextualizar la formación socioespacial del sitio estudiado. Los resultados muestran que el contexto socioespacial de la región investigada contribuye significativamente a la expansión y reconfiguración de la actividad turística y, en consecuencia, también contribuye al desarrollo regional.

Palabras clave: Aspectos socioespaciales; Alto Vale do Itajaí; Acolhida na Colônia.

\section{INTRODUÇÃO}

Santa Catarina recebe atualmente um dos maiores fluxos turísticos do país. 0 estado possui uma grande diversidade de atrativos, paisagens e tradições culturais que beneficiam suas regiões turísticas: Caminho dos Príncipes, Vale do Contestado, Grande Oeste, Costa Verde e Mar, Vale Europeu, Grande Florianópolis, Encantos do Sul, Caminho dos Cânions e Serra Catarinense.

0 estado divide-se em seis macrorregiões: Grande Florianópolis, Norte Catarinense, Oeste Catarinense, Serrana, Sul Catarinense e Vale do Itajaí, sendo que nesta última fica localizada a região turística denominada Vale Europeu.

Na região do Alto Vale do Itajaí, vários municípios estão desenvolvendo atividades turísticas, com destaque para Apiúna, Ibirama, Presidente Getúlio, Presidente Nereu, Witmarsum e Vitor Meireles, que fazem parte do projeto Acolhida na Colônia, direcionado ao turismo rural em que as famílias de agricultores imigrantes europeus recebem os turistas em suas propriedades e apresentam seu modo de viver junto à natureza (Acolhida na Colônia, 2007).

0 projeto Acolhida representa um esforço de atender, em termos mercadológicos, às novas complexidades que envolvem o avanço e a atualização do turismo e exigem das organizações preparo e adaptação para enfrentar as transformações ocorridas no mundo contemporâneo, caracterizado por significativas mudanças no perfil dos clientes.

Esta pesquisa objetiva discutir a gênese e os aspectos socioespaciais do Alto Vale do Itajaí e, mais especificamente, dos municípios que compõem o projeto Acolhida na Colônia, visando a compreender os aspectos que antecederam o momento atual e contribuíram para a inserção das cidades no projeto.

Um estudo de formação socioespacial deve apresentar a materialidade concreta expressa pelo local, investigando e definindo suas características naturais e o processo histórico responsável por seu estado atual (Santos, 1982).

Diante da perspectiva da formação socioespacial influenciada por múltiplas determinações, é possível analisar, conforme Mamigonian (1966), a especificidade histórica e geográfica de cada lugar sem abandonar o conhecimento do 
conjunto. Sendo assim, este trabalho utiliza, como método de análise, o paradigma de formação socioespacial de Santos (1982), que sugere o conceito de formação social como base para o estudo da sociedade. Dessa forma, para estudar a gênese do Alto Vale do Itajaí, faz-se necessário falar previamente de Santa Catarina, inserindo a região no contexto maior do estado catarinense.

Depois de contextualizar a região do Vale do Itajaí, a abordagem se voltará ao Alto Vale do Itajaí - mais precisamente, para os municípios de Vitor Meireles, Witmarsum, Presidente Getúlio, Lontras, Presidente Nereu e Ibirama, nos quais está inserido o projeto Acolhida na Colônia, iniciado em 1998 na região das encostas da Serra Geral de Santa Catarina e expandido somente em 2005 para a microrregião do Alto Vale, cujos primeiros colonizadores foram alemães e italianos.

Este estudo pode ser relevante na medida em que procura contribuir para o melhor entendimento do processo de transformação de uma sociedade por meio de caracterizações de espaço e tempo.

\section{METODOLOGIA}

Este trabalho caracteriza-se como um estudo de caso, com pesquisa descritiva e bibliográfica, que propõe uma discussão dialética a fim de contextualizar os aspectos socioespaciais e a gênese da região do Alto Vale do Itajaí, com destaque para os municípios de Apiúna, Ibirama, Lontras, Presidente Getúlio, Presidente Nereu, Witmarsum e Vitor Meireles, envolvidos no projeto Acolhida na Colônia.

A revisão bibliográfica baseou-se em fontes de dados secundários, como artigos de periódicos, livros, teses e dissertações. 0 levantamento de informações foi realizado no mês de abril de 2016, por meio de consulta, no site da Acolhida na Colônia (2007), sobre as propriedades pertencentes à instituição. Em paralelo, um questionário que solicitava uma lista atualizada das propriedades e dos principais atrativos dos munícipios da Acolhida foi encaminhado, via correspondência eletrônica, para a assessoria técnica responsável pela regional. Segundo os levantamentos da pesquisa, pertencem à regional de Ibirama: uma propriedade no município de Apiúna; duas propriedades em Presidente Getúlio; duas propriedades em Presidente Nereu; duas propriedades no município de Witmarsum e duas propriedades em Vitor Meireles.

\section{ASPECTOS SOCIOESPACIAS DO ALTO VALE DO ITAJAÍ}

Santa Catarina é um estado que se destaca pelo bom índice de desenvolvimento socioeconômico e pela geografia privilegiada. Do ponto de vista socioeconômico, o estado "possui duas formações bem diferentes: as áreas de colonização europeia, sobretudo alemã e italiana, nascidas de pequenas propriedades no século XIX e as áreas de latifúndio pastoril" (Mamigonian, 2011, p. 79).

O estudo aborda as áreas de colonização europeia na região do Vale do Itajaí e, mais detalhadamente, do Alto Vale, conforme destaque no mapa (Figura 1). 
Figura 1 - Área de cobertura da região do Alto Vale do Itajaí

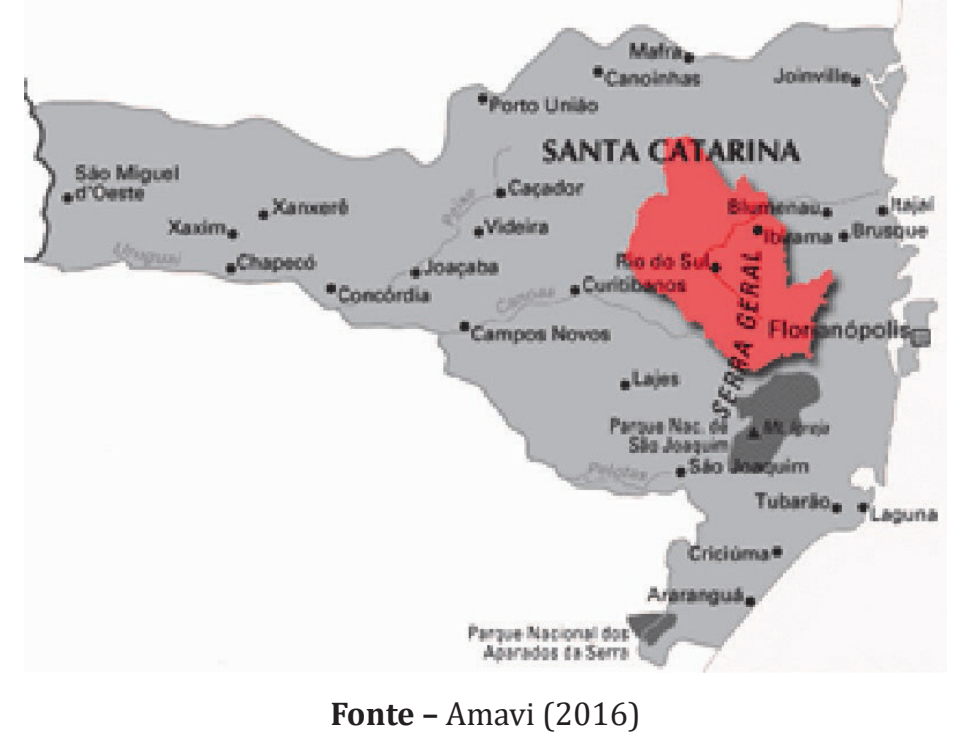

A imigração dos europeus ocorreu após a abolição da escravatura, quando vieram substituir os escravos nas lavouras de café (Singer, 1984).

Em 1829, a colonização alemã se estabeleceu em Santa Catarina, na Colônia de São Pedro de Alcântara, próxima à capital Desterro. Já o Vale do Itajaí foi colonizado por alemães em 1850, com a fundação da colônia do Dr. Hermann Blumenau, na confluência do Ribeirão da Velha com o rio Itajaí-Açu. Esse projeto impulsionou os alemães a se estabelecerem em Santa Catarina.

A região Dona Francisca (Joinville) foi colonizada no ano de 1851, enquanto a região de Itajaí (Brusque) foi fundada em 1860 e, nesse mesmo ano, o governo imperial assumiu a colônia de Blumenau (Rost, 2008).

0 Vale do Itajaí conta com três subdivisões: o Alto Vale, o Médio Vale e a Foz do Itajaí. O Alto Vale foi colonizado no final do século XIX e início do XX (Haas Jr., 2009). Situada no local, a colônia Blumenau foi criada em 1850 e logo se expandiu para Timbó e Indaial por volta de 1870, para Ibirama no ano de 1890 e para Rio do Sul em 1910.

Nessas colônias, as relações sociais eram diferentes das existentes nas regiões do Litoral e da Serra. As relações produtivas eram muito mais intensas, pois os imigrantes de origem europeia tinham como objetivo principal melhorar sua condição econômica. Com sua cultura e conhecimento, os colonos marcaram a região profundamente com o espírito do capitalismo, conforme definido por Max Webber (Santos, 2000).

Segundo Santos (2000), o objetivo da imigração visava basicamente exploração agrícola em áreas rurais que tinham uma medida padrão de aproximadamente 25 ha para acolher uma família.

Em regra, os imigrantes eram jovens. Assentados em seus lotes, tendo parentes ou amigos como vizinhos, tratavam de desbravar a terra, para logo realizarem as primeiras culturas. As administrações das colônias, asseguravam uma certa base para garantir a sobrevivência dos recém-chegados. Muitos imigrantes foram envolvidos na abertura de estradas, ou de outras obras, com o objetivo de lhes assegurar alguns ganhos. (Santos, 2000, p. 113) 
Além do trabalho na agricultura e serviços nas obras, Pereira (2003) destaca o comércio de produtos agrícolas excedentes e a oferta de serviços essenciais que foram introduzidos pela colonização alemã em Santa Catarina.

Os colonos alemães iniciaram uma diversificada pequena produção mercantil rural (produtos alimentares, tais como manteiga, banha, leite, queijo) e urbana (atividades de artesãos, como ferreiros, marceneiros, tecelões, alfaiates, sapateiros). Ao comercializarem o excedente de sua produção adquiriam através do sistema colônia-venda outras mercadorias, imprimindo um dinamismo que, articulado às complexas relações econômicas, sociais e espaciais inter e extrarregionais decorrentes da evolução do capitalismo no Brasil e no mundo, propiciou o surgimento e a consolidação de um vigoroso parque industrial. (Pereira, 2003, p. 108)

As atividades primárias impulsionaram o surgimento de um parque industrial centrado na produção de alimentos e de madeira que se mantém até hoje em vários municípios, contribuindo de modo significativo para o desenvolvimento socioeconômico apresentado no Quadro 1 (Menezes \& Vieira, 2010).

Quadro 1 - Fases do processo de formação socioeconômica do Alto Vale do Itajaí

\begin{tabular}{|c|c|c|c|c|}
\hline \multicolumn{5}{|c|}{ Periodização e evolução da socioeconomia do Alto Vale do Itajaí } \\
\hline Período & $1850-1920$ & $1920-1960$ & 1960-1990 & $1990-2000$ \\
\hline Ênfase & $\begin{array}{l}\text { Processo de } \\
\text { formação das } \\
\text { vilas; } \\
\text { - Economia de } \\
\text { subsistência } \\
\text { e cooperação } \\
\text { (extrativismo/ } \\
\text { agricultura) }\end{array}$ & $\begin{array}{l}\text { - Extrativismo } \\
\text { madeireiro; } \\
\text { - Agricultura e } \\
\text { cooperativismo; } \\
\text { - Surgimento de } \\
\text { alguns setores. }\end{array}$ & $\begin{array}{l}\text { - Crise do setor } \\
\text { madeireiro; } \\
\text { - Busca de } \\
\text { alternativas para } \\
\text { a região; } \\
\text { - Surgimento } \\
\text { das primeiras } \\
\text { empresas do } \\
\text { segmento - fruto } \\
\text { da proximidade } \\
\text { com o Médio } \\
\text { Vale. }\end{array}$ & $\begin{array}{l}\text { - Ascensão e } \\
\text { proliferação de } \\
\text { MPEs do setor } \\
\text { têxtil e vestuário; } \\
\text { - Fortalecimento } \\
\text { de outros setores. }\end{array}$ \\
\hline Problemas & $\begin{array}{l}\text { - Dificuldade de } \\
\text { transporte }\end{array}$ & $\begin{array}{l}\text { Dificuldade de } \\
\text { transporte e } \\
\text { acesso à energia } \\
\text { elétrica }\end{array}$ & $\begin{array}{l}\text { Exxodo das } \\
\text { pessoas e de } \\
\text { empresas / } \\
\text { capitais }\end{array}$ & $\begin{array}{l}\text { - Êxodo agrícola; } \\
\text { - Enfraquecimento } \\
\text { da cultura e do } \\
\text { cooperativismo } \\
\text { local }\end{array}$ \\
\hline
\end{tabular}

Fonte - Adaptado de Menezes e Vieira (2010, p. 198)

O papel de destaque logo alcançado pelos núcleos de colonização europeia pode ser explicado pelo fato de que "os imigrantes trazem para a América, na condição de proprietários rurais, artesãos, operários ou pequenos empresários, o capitalismo 'em seus ossos'”' (Mamigonian, 1976, p. 89).

Os primeiros anos do desenvolvimento da colônia alemã no Vale do Itajaí foram marcados por grandes dificuldades: a necessidade de adaptação às diversidades locais, o número reduzido de imigrantes, a falta de capital e mão de obra, a escassez de investimentos e as frequentes enchentes que aconteciam na região, causando graves prejuízos - obstáculos que acabavam por limitar o 
empreendimento colonizador. Conforme Silva (2002), muito embora a ocupação do espaço, a formação da estrutura agrícola e o desenvolvimento do Vale do Itajaí tenham sido marcados pelos descontínuos fluxos de imigrantes alemães, a falta de recursos públicos e dificuldades comuns a outras regiões brasileiras não afetou a região, que logo se projetou, com seu dinamismo socioeconômico, no cenário estadual e nacional.

Depois da vinda dos alemães, os italianos, no final do século XIX, povoaram as bordas de áreas ocupadas no Vale do Itajaí e fundaram, no litoral sul de Santa Catarina, novos núcleos coloniais que se expandiram através da agricultura e da mineração do carvão. A ocupação do território catarinense completa-se no início do século XX com a comercialização de terras no Oeste, num processo de colonização e povoamento para descendentes de alemães e italianos que vieram do Rio Grande do Sul (Pereira, 2001).

Os alemães se fixaram em Blumenau e arredores, que atualmente pertencem aos municípios de Gaspar, Pomerode, Massaranduba, Indaial, Timbó e Ibirama. Os italianos se fixaram nos municípios de Luiz Alves, Rio dos Cedros, Rodeio, Apiúna, Ascurra e na primeira colônia do Alto Vale, Ibirama, inicialmente conhecida como colônia Hamônia, instalada na confluência dos rios Itajaí-Açu e Itajaí do Norte, marco do início das empresas colonizadoras no Alto Vale por meio de empreendimentos cujo objetivo era agenciar a venda de terras (Haas Jr., 2009).

A região possui uma diversidade de atrativos turísticos, dentre os quais se destacam a gastronomia, a arquitetura e os eventos típicos, reflexos das tradições e dos costumes de seus colonizadores.

\section{Turismo no Alto Vale do Itajaí: Acolhida na Colônia}

Muitos autores definem o turismo como uma atividade meramente econômica. De acordo com Luca Filho (2014), o turismo é uma atividade socioeconômica, que assume lugar de destaque na economia de um país, de uma região ou localidade na medida em que gera a produção de bens e serviços que visam à satisfação de necessidades básicas (e desejos) dos consumidores, como alimentação, hospedagem, transporte e lazer.

Nesse mesmo contexto, De La Torre (1997) evidencia a importância do turismo na esfera social, econômica e cultural, transcendendo setores exclusivamente comerciais.

Turismo é um fenômeno social que consiste no deslocamento temporário e voluntário de um ou mais indivíduos que, por uma complexidade de fatores que envolvem a motivação humana, saem de seu local de residência habitual para outro, no qual não exerçam atividades lucrativas ou remuneradas, gerando múltiplas inter-relações de importância cultural, socioeconômica e ecológica entre os núcleos emissores e receptores (Mota, 2001, p. 43).

Em função da lentidão da chegada dos meios de transportes e da dificuldade em consolidar estradas, criadas como rotas independentes, o turismo de Santa Catarina, assim como as outras atividades econômicas, demorou a desenvolver-se 
(Mamigonian, 1966). Em seu início, a atividade turística do local voltou-se ao turismo de sol e mar.

Com o intuito de promover outras regiões do estado surgem os projetos de interiorização do turismo, com destaque para o Alto Vale do Itajaí e seus atrativos. 0 associativismo municipal representado pela Associação dos Municípios do Alto Vale do Itajaí (Amavi) tem importância fundamental nesse processo (Poleza, Butzke, \& Rischbieter, 2008). A associação iniciou suas atividades na década de 1960, quando prefeitos de vinte pequenos municípios da região buscaram, através da criação do associativismo, uma alternativa para o atendimento de causas regionais e o enfrentamento de problemas complexos de ordem estrutural, organizacional, social, econômica e administrativa (Amavi, 2005). Hoje, a Amavi é formada por 28 municípios.

0 projeto Acolhida na Colônia, segundo Baum, Canteri e Trzaskos (2012), foi criado em 1998, por Thaise Guzzatti, com o intuito de promover a estabilidade dos municípios da região das encostas da Serra Geral de Santa Catarina, que vinham sofrendo com o êxodo rural. A iniciativa foi inspirada na rede francesa de agroturismo Accueil Paysan, atuante desde os anos 1980.

Conforme Baum et al. (2012), a associação é representada por trinta municípios de Santa Catarina inseridas em aproximadamente 180 propriedades de famílias rurais numa rede de desenvolvimento comunitário, solidário e sustentável que compreende os seguintes princípios:

a parte integrante do estabelecimento rural é o agroturismo e se constitui num fator de desenvolvimento local; os agricultores desejam compartilhar com os turistas o ambiente onde vivem, sendo que a recepção e convívio dos mesmos devem ocorrer num clima de troca de experiência e respeito mútuo; o agroturismo deve praticar preços acessíveis; os serviços agroturísticos são planejados e organizados pelos agricultores familiares, que garantem a qualidade dos produtos e serviços que oferecem. (Baum et al., 2012 p. 5)

Com base nesses princípios, o projeto foi introduzido em Santa Catarina na região das encostas da Serra Geral, atuando nos municípios de Anitápolis, Gravatal, Imbituba, Rancho Queimado, Santa Rosa de Lima e São Bonifácio. Na região de Ituporanga, compreende os municípios de Aurora e Atalanta; na região do Vale dos Imigrantes, compreende os municípios de Agrolândia, Agronômica e Rio do Sul; na Serra Catarinense, os municípios de Urubici e São Joaquim.

Os municípios que compõem o projeto Acolhida na Colônia são: Apiúna, Presidente Getúlio, Presidente Nereu, Vitor Meireles e Witmarsum, conforme apresentado na Figura 2. São pequenos agricultores que se uniram para buscar outras fontes de renda por meio de atrativos turísticos voltados ao meio agrícola. 0 município de Apiúna pertence ao Médio Vale do Itajaí. 
Figura 2 - Alto Vale do Itajaí: Municípios que pertencem à regional de Ibirama (Acolhida na Colônia)

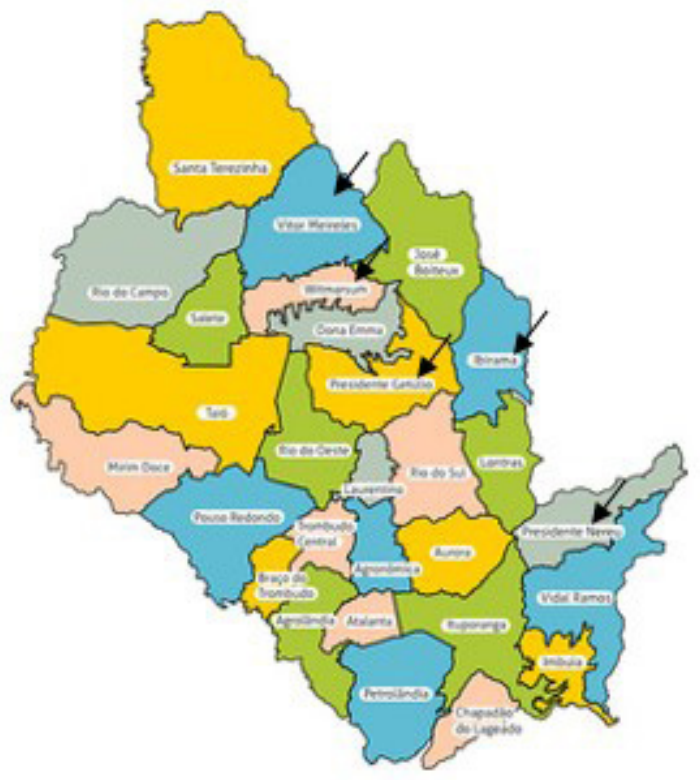

Fonte - Adaptado de Amavi (2017a)

\section{Aspectos socioespaciais dos municípios que compõem o projeto Acolhida na Colônia}

No ano de 1897, imigrantes alemães da Sociedade Colonizadora Hanseática ocuparam Ibirama com uma expedição chefiada pelo diretor da Sociedade, Alfred Sellin, que fundou a sede da colônia, dando-lhe o nome de Hamônia. 0 município foi emancipado em 1934. Somente no ano de 1934, passou a ser denominado Ibirama. (Ibirama, 2017). Atualmente, conta com uma população estimada de 18.567 habitantes, segundo o IBGE (2017).

O município de Presidente Getúlio foi fundado no ano de 1904, com a chegada, por meio da Sociedade Colonizadora Hanseática, de imigrantes suíços que inicialmente nomearam o local como Neu Zürich (Presidente Getúlio, 2016). Em 1934, seu nome foi modificado para Dalbérgia, mas em seguida voltou a denominar-se Neu Zürich, Getúlio Vargas e, finalmente, no ano de 1953, passou a ser conhecido como Presidente Getúlio (Amavi, 2017b), contando atualmente com uma população estimada de 16.736 habitantes (IBGE, 2017).

Em abril de 1876, foi registrado pelo engenheiro João Maria de Almeida Portugal o projeto da Vila de Aquidaban, colonizada por imigrantes italianos, depois por alemães e, mais tarde, por portugueses oriundos das ilhas dos Açores e de Madeira. 0 município foi denominado Apiúna em janeiro de 1944 (Apiúna, 2007). Atualmente, possui uma população estimada de 10.432 habitantes, segundo o IBGE (2017).

O fundador de Presidente Nereu, José da Costa Miranda, foi designado pela diretoria da Colonização de Terras do Estado para localizar e demarcar a colônia agrícola de Edelberto Brasilides de Oliveira. Em julho de 1928, Antônio Fernando Joenck, primeiro morador do município, instalou-se no local, denominado inicialmente como Vila d'Alva. 0 local teve oito nomes diferentes antes de adotar o 
nome atual, Presidente Nereu, em homenagem ao único presidente da República nascido em Santa Catarina (Presidente Nereu, 2015). O município conta com uma população de apenas 2.306 habitantes, conforme o IBGE (2017).

A história de Vitor Meireles iniciou no ano de 1935, com a chegada dos primeiros imigrantes. Nascia então o povoado de Rio Preso, que recebeu este nome pelo fato de o rio estar localizado entre barrancos e matas. Em 1945, o povoado passou a se chamar Alto Rio Dollmann e, depois, foi denominado Forcação, pois seus rios Fachinal e Palmitos formavam a figura de uma forca. No ano de 1967, o escrivão Alceste Moser sugeriu, por meio de um projeto enviado à Câmara de Vereadores do município de Ibirama, a mudança do nome da cidade para Vitor Meireles, em homenagem ao famoso pintor catarinense. No dia 26 de abril de 1989, o município, desmembrando de Ibirama pela Lei 7.579/89, passou a se chamar Vitor Meireles (Vitor Meireles, 2014). Atualmente, conta com uma população estimada de 5.089 habitantes (IBGE, 2017).

O município de Witmarsum iniciou sua história em 1924 com a vinda de soldados alemães para o interior do distrito de Hamônia (atual Ibirama). Excombatentes no continente africano, os soldados inicialmente nomearam o local como Nova África. Após seis anos, chegaram imigrantes russos vindos da Ucrânia que mudaram o nome do lugar para Witmarsum. 0 local tornou-se distrito de Presidente Getúlio quando este se desmembrou de Ibirama. O município se emancipou somente em 1962 (Witmarsum, 2016). Conforme o IBGE (2017), a cidade possui atualmente uma população estimada de apenas 3.876 habitantes.

\section{Atrativos turísticos}

Por meio de pesquisa no site da Acolhida (2007 e de aplicação de questionário respondido via correspondência eletrônica pela assessoria técnica do projeto, foi realizado o levantamento sobre a localização e as características dos atrativos turísticos da região.

Verificou-se que atualmente fazem parte do projeto Acolhida na Colônia os municípios de Apiúna, Presidente Getúlio, Presidente Nereu, Vitor Meireles e Witmarsum. 0 município de Apiúna tem, como opção de visita, a Pousada Recanto dos Bugios. Em Presidente Getúlio, o turista pode conhecer o Recanto das Abelhas e o Recanto dos Saberes e Sabores. Presidente Nereu oferece dois atrativos: o Sítio Colina e o Sítio Vida Nova. Já em Vitor Meireles, é possível visitar o Recanto Cardozo e o Recanto Natural, e, em Witmarsun, a Pousada Recanto da Natureza e o Sítio Warmeling.

Em Apiúna, a Pousada Recanto dos Bugios oferece aos visitantes um tradicional café colonial preparado em fogão a lenha. Os proprietários mantêm no local a produção orgânica de frutas, hortaliças e mel. 0 turista também pode se aquecer do friozinho da serra junto à lareira ou fogão a lenha, além de realizar caminhadas ao ar livre em meio à mata nativa, fazer trilhas, passeios de tobata e visitas a cachoeiras.

Na localidade de Presidente Getúlio, como dito anteriormente, o turista tem duas opções de visita: Recanto das Abelhas e Recanto dos Saberes e Sabores. No Recanto das Abelhas, o casal de agricultores e sua família desenvolvem produtos orgânicos e são comprometidos com a recuperação e preservação ambiental. No 
espaço, o turista pode conhecer o trabalho de recuperação da mata ciliar, aprender como usufruir economicamente das florestas de forma sustentável e acompanhar a colheita de frutos como o açaí. Os agricultores criam diversas espécies de abelhas nativas, disponibilizando ao turista vários tipos de mel que podem ser provados e levados para casa. Além disso, o turista pode passear pela propriedade, observar lagos, aves criadas ao ar livre, apreciar especialidades culinárias como pães, doces, geleias, mel, suco de açaí, carne de galinha ensopada com aipim e fazer passeios de tobata até uma trilha ecológica, onde é possível observar espécies nativas. Outra opção é o banho relaxante em uma cascata cercada pela Mata Atlântica, próxima à propriedade.

Já no Recanto dos Saberes e Sabores, a proprietária do local gosta de compartilhar com o visitante seu conhecimento sobre plantas medicinais e terapias alternativas, mostrando sua diversificada produção e oferecendo uma massagem terapêutica. 0 local possui a trilha dos sentidos, com flores vermelhas, laranjas, amarelas, verdes e azuis, representando as cores utilizadas na cromoterapia. Passeando por entre plantas e flores, o turista pode sentir uma infinidade de aromas. Pode-se também pescar, colher frutas ou simplesmente contemplar a natureza ouvindo o canto dos pássaros e o vento tocando as árvores.

Originalmente um rancho que servia de depósito para ferramentas e abrigo de animais, o Sítio Colina, localizado em Presidente Nereu, foi transformado em um belo restaurante colonial, decorado pelos proprietários com produtos do próprio local. A preocupação da família proprietária com o meio ambiente e com a agroecologia pode ser observada no círculo de bananeiras e na horta-mandala orgânica. Além de almoços e jantares deliciosos, é servido aos visitantes um bolo de fubá com um cafezinho feito no fogão a lenha. $\mathrm{O}$ ambiente proporciona paz e tranquilidade aos visitantes. Nessa localidade, também é possível percorrer uma trilha que leva a uma bela cachoeira, passear de tobata ou pescar no lago.

O Sítio Vila Nova, que tem grande parte de sua área coberta pela Mata Atlântica, preservada entre os contrafortes da Serra do Mar, apresenta vários atrativos aos turistas, como a possibilidade de participar de conversas em rodas de chimarrão, ouvir histórias e contos à beira da lareira, conhecer os afazeres, os costumes e o estilo de vida da tradição colonial e experimentar refeições típicas, com ingredientes genuínos da roça e modo de preparo artesanal. Outro atrativo é o minimuseu, onde estão expostos objetos antigos e artefatos históricos que fazem parte da decoração da casa principal da propriedade, como a coleção de relógios antigos e de louças com peças do século XVII, artefatos persas e africanos e mobílias. A casa ainda oferece aos hóspedes quartos confortáveis e suítes avarandadas com vista para o jardim e para as montanhas, um verdadeiro convite para relaxar e curtir a paisagem. 0 local proporciona oficinas de sabonetes artesanais e culinária, nas quais o visitante tem a oportunidade de aprender sobre a história e origem das receitas. 0 turista pode ainda fazer caminhadas, passeios pelas trilhas, subidas à montanha, observar a natureza, desfrutar da água de nascentes de pequenos riachos que descem direto da montanha, pescar nas lagoas ou apenas observar os gansos e patos selvagens, participar dos afazeres do dia a dia, ajudando a preparar as refeições, tirar leite das vacas e colher frutas e hortaliças na roça, ou simplesmente deitar na rede e relaxar.

Na cidade de Vitor Meireles, o Recanto Natural, localizado na reserva ambiental Arie (Área de Relevante Interesse Ecológico), oferece aos turistas a possibilidade 
de observar diversas espécies da fauna e flora locais (tucano, gralha-azul, gralha-amarela, papagaio-de-peito-roxo etc.), realizar passeios a cavalo, caminhar ao ar livre e desfrutar da culinária típica. No Recanto Cardozo, também localizado na reserva ambiental, além de observar a natureza, o turista pode saborear comidas tradicionais, feitas com produtos da horta orgânica do local, e ainda levar para casa conservas de frutas da época.

Em Witmarsum, o visitante tem a opção de se hospedar na pousada Recanto da Natureza e saborear a culinária típica, feita com produtos fresquinhos da horta. Na propriedade existe o cultivo de frutas como amoras, morangos e horta orgânica e produção de artesanatos, vinho, geleias, sucos, licores, queijos, entre outros produtos coloniais. Entre as atividades oferecidas ao turista estão disponíveis o passeio pelo pomar de amoras e morangos, a colheita de verduras e legumes fresquinhos para o almoço e a pesca em lagoa.

Witmarsum também oferece, como atrativo turístico, o Sítio Warmeling, cujos proprietários são típicos agricultores do interior de Santa Catarina, de descendência alemã e alto nível de consciência ecológica. Além de atenderem os visitantes, fabricam vinho, sucos, geleias e compotas artesanais e se dedicam também ao pomar de pêssego, uva e caqui, bem como ao trabalho no campo. Durante a safra de pêssegos, oferecem aos visitantes a atividade de "Colha e Pague". 0 turista pode também fazer trilhas pela propriedade.

Do ponto de vista de Baum, Canteri e Trzaskos (2012), as famílias de agricultores têm a oportunidade de preservar e valorizar as experiências que foram transmitidas de geração para geração quando passam a ensinar os turistas sobre como viver de forma mais sustentável. Na Colônia, o turista pode aprender sobre a produção de alimentos orgânicos, colaborando na preparação e degustação das refeições.

Na Tabela 1, é apresentado um resumo dos principais atrativos de cada destino.

Tabela 1 - Levantamento dos principais atrativos do projeto Acolhida na Colônia

\begin{tabular}{|c|c|c|}
\hline Município & Destinos & Principais Atrativos \\
\hline Apiúna & $\begin{array}{l}\text { Pousada Recanto } \\
\text { do Bugios }\end{array}$ & $\begin{array}{l}\text { - Gastronomia típica e orgânica; } \\
\text { - Caminhadas ao ar livre; } \\
\text { - Passeios de tobata; } \\
\text { - Trilhas para visitar cachoeiras. }\end{array}$ \\
\hline $\begin{array}{l}\text { Presidente } \\
\text { Getúlio }\end{array}$ & $\begin{array}{l}\text { Recanto das } \\
\text { Abelhas }\end{array}$ & $\begin{array}{l}\text { - Conhecimentos sobre produção de alimentos orgânicos; } \\
\text { - Educação ambiental; } \\
\text { - Prilha ecológica; } \\
\text { - Banho de cascata; } \\
\text { - Acompanhamento da colheita de açaí; } \\
\text { - Passeios de tobata; } \\
\text { - Observação das espécies nativas, } \\
\text { - Culinária típica e orgânica. }\end{array}$ \\
\hline $\begin{array}{l}\text { Presidente } \\
\text { Getúlio }\end{array}$ & $\begin{array}{l}\text { Recanto dos } \\
\text { Saberes e Sabores }\end{array}$ & $\begin{array}{l}\text { - Aprendizado sobre plantas terapêuticas; } \\
\text { - Massagem terapêutica; } \\
\text { - Passeio pela trilha dos sentidos com flores de várias cores } \\
\text { e aromas; } \\
\text { - Pescaria; } \\
\text { - Observação da natureza. }\end{array}$ \\
\hline
\end{tabular}




\section{Tabela 1 - Continuação}

\begin{tabular}{|c|c|c|}
\hline Município & Destinos & Principais Atrativos \\
\hline \multirow[b]{2}{*}{$\begin{array}{l}\text { Presidente } \\
\text { Nereu }\end{array}$} & Sítio Colina & $\begin{array}{l}\text { - Culinária da região; } \\
\text { - Café colonial preparado em fogão à lenha; } \\
\text { - História de vida dos agricultores; } \\
\text { - Conforto de uma lareira para os dias de frio; } \\
\text { - Colheita e degustação de frutas e hortaliças da época; } \\
\text { - Educação ambiental, agroecologia; } \\
\text { - Trilha até a cachoeira; } \\
\text { - Passeio de tobata; } \\
\text { - Pescaria no lago. }\end{array}$ \\
\hline & Sítio Vida Nova & $\begin{array}{l}\text { - Conversa em roda de chimarrão; } \\
\text { - Histórias e contos à beira da lareira; } \\
\text { - Refeições típicas com preparo artesanal; } \\
\text { - Minimuseu com exposição de objetos antigos e artefatos } \\
\text { históricos; } \\
\text { - Caminhadas pelas trilhas, montanha e riacho; } \\
\text { - Observação da paisagem e de animais; } \\
\text { - Preservação do meio ambiente; } \\
\text { - Pescaria nas lagoas; } \\
\text { - Participação nos afazeres do dia a dia: preparar as } \\
\text { - } \text { refeições, tirar leite e colher frutas e hortaliças na roça; } \\
\text { - Festas da comunidade e jantares temáticos, como a Noite } \\
\text { Árabe, Pizza da Roça e Jantar Cultural; } \\
\text { - Suítes e quartos aconchegantes; } \\
\text { - Apresentação de gaiteiros e violeiros que resgatam a } \\
\text { música caipira; } \\
\text { - Degustação de vinhos e chopes artesanais; } \\
\text { - Pratos para vegetarianos, celíacos, alimentos naturais e } \\
\text { dieta de desintoxicação (detox). }\end{array}$ \\
\hline \multirow{2}{*}{$\begin{array}{l}\text { Vitor } \\
\text { Meireles }\end{array}$} & Recanto Natural & $\begin{array}{l}\text { - Pratos típicos; } \\
\text { - Observação da fauna e da flora, área de preservação } \\
\text { ambiental; } \\
\text { - Passeios a cavalo; } \\
\text { - Caminhadas ao ar livre. }\end{array}$ \\
\hline & Recanto Cardozo & $\begin{array}{l}\text { - Culinária típica; } \\
\text { - Produtos da horta orgânica; } \\
\text { - Conservas de frutas da época; } \\
\text { - Observação da natureza. }\end{array}$ \\
\hline \multirow{2}{*}{ Witmarsun } & $\begin{array}{l}\text { Pousada Recanto } \\
\text { da Natureza }\end{array}$ & $\begin{array}{l}\text { - Passeio pelo pomar de amoras e morangos; } \\
\text { - Colheita de verduras e legumes fresquinhos; } \\
\text { - Observação e pescaria na lagoa. }\end{array}$ \\
\hline & Sítio Warmeling & $\begin{array}{l}\text { - Colheita de pêssegos, } \\
\text { - Compra de compotas, geleias, vinhos artesanais; } \\
\text { - Passeio pelo sítio. }\end{array}$ \\
\hline
\end{tabular}

Fonte - Elaborado pelos autores (2016) 


\section{CONSIDERAÇÕES FINAIS}

Utilizando, como método de análise, o paradigma de formação socioespacial de Santos (1982), que sugere o uso do conceito de formação social como base para o estudo da sociedade, buscou-se apresentar, neste trabalho, a materialidade concreta expressa pelo local estudado, com o estudo de sua gênese e a definição de suas características naturais e do processo histórico responsável por sua formação.

A análise dos dados apresentados sobre a formação socioespacial da região de Ibirama permite concluir que, a partir de transformações dos recursos existentes e da organização socioespacial, os agricultores enxergaram uma nova possibilidade de negócio no meio rural em que vivem e do qual retiram seu sustento, passando a investir no setor de turismo como mais uma opção de renda familiar.

Neste estudo, aponta-se também que o turista pode usufruir de diferentes atrativos em cada um dos destinos investigados. Dos nove locais, oito apresentam, como destaque, atrativos relacionados à cultura local, tais como: gastronomia típica, histórias de antepassados, resgate da música caipira e exposição de objetos, móveis antigos e artefatos históricos.

Seis propriedades direcionam seus atrativos para os turistas que buscam aprender sobre a história do lugar, ofertando dicas sobre educação ambiental, plantas terapêuticas, produção de alimentos orgânicos, oficinas de culinária e de produtos artesanais, exposição de objetos, móveis e artefatos históricos que reforçam a cultura local.

Outras propriedades estão mais voltadas a atividades realizadas na própria natureza, como observação, caminhadas ao ar livre, trilhas, pescaria no lago, banho de cascata, passeios de tobata, degustação de vinho e chope artesanal e massagem terapêutica. Além disso, algumas das propriedades investigadas apresentam atividades que envolvem a participação nos afazeres do dia a dia, como preparo das refeições, ordenha de vacas, colheita de frutas e verduras e participação nas oficinas de culinária e de produtos artesanais.

Verificou-se também que os proprietários estão tentando diversificar seus atrativos a fim de contemplar diferentes gostos, com a oferta de pratos para vegetarianos e celíacos e dieta de desintoxicação (detox), apresentação de gaiteiros e violeiros, festas da comunidade e jantares temáticos.

A riqueza cultural, natural e arquitetônica da região acaba contribuindo com os gestores na criação e planejamento dos principais atrativos a serem apresentados aos turistas. Percebe-se que essa mudança no cenário da região traz uma maior valorização da cultura e produção local. Os agricultores continuam a trabalhar na agricultura, agora aliada à atividade econômica turística.

Desse modo, torna-se evidente que todo o contexto socioespacial da região investigada contribui de forma significativa para a expansão e reconfiguração da atividade econômica voltada ao turismo e, por consequência, para o desenvolvimento regional. 


\section{REFERÊNCIAS}

Acolhida na Colônia. (2007). Regional de Ibirama. Recuperado de http://bit.ly/2qSVpVm Amavi. (2005). Histórico. Recuperado de http://bit.ly/2qdfnLo Amavi. (2017a). Localização e distâncias. Recuperado de http://bit.ly/2qeeXQT

Amavi. (2017b). Resgate do patrimônio histórico: Presidente Getúlio. Recuperado de http://bit.ly/2reCjtW

Apiúna. (2007). Câmara de Vereadores. História. Recuperado de http://bit.ly/2qcWRmD

Baum, J., Canteri, K.C., \& Trzaskos, L. A. (2012). Sustentabilidade turística e suas iniciativas: análise do projeto Acolhida na Colônia para a região turística Campos Gerais. In Anais do VI Fórum Internacional de Turismo do Iguassu. GT2 - Eixo Estruturante Cultural no Turismo e Hospitalidade (n.d.). Foz do Iguaçu, PR. Recuperado de http://festivaldeturismodascataratas.com

De La Torre, O. P. (1997). El turismo: fenómeno social (2ae ed.). México: Fondo de Cultura Ecónomica, Sección de obras de sociología.

Haas Jr., A. (2009). A Amavi e o Projeto Resgate do Patrimônio Histórico: identidade regional e A indústria do turismo: Alto Vale do Itajaí - SC (2006-2009). In Anais do IV Congresso Internacional de História (pp. 3863-3874). Maringá, PR. doi: 10.4025/4CIH.PPHUEM.348

IBGE. (2017). Cidades. Recuperado de http://bit.ly/2rQAFLX

Ibirama. (2017). Prefeitura Municipal. A história de Ibirama. Recuperado de http://bit. ly/2ri0CqS

Luca Filho, V. (2014). A geografia das feiras de negócios em Santa Catarina: origem, evolução e dinâmica das transformações (Tese de doutorado). Centro de Filosofia e Ciências Humanas, Universidade Federal de Santa Catarina, Florianópolis, SC. Recuperado de http://bit.ly/2qPV5q9

Mamigonian, A. (1966). Vida regional em Santa Catarina. Revista Orientação, (2), 35-38.

Mamigonian, A. (1976). 0 processo de industrialização em São Paulo. Boletim Paulista de Geografia, 50, 83-101.

Mamigonian, A. (Org.). (2011). A indústria de Santa Catarina: dinamismo e estrangulamento. Santa Catarina: estudos e geografia econômica e social (Vol. 4, Série Livros Geográficos). Florianópolis: Departamento de Geociências UFSC.

Menezes, E. C. O., \& Vieira, P. H. F. (2010). Impactos socioambientais da indústria do vestuário sobre a atividade agrícola no Alto Vale do Itajaí - Santa Catarina. IDeAS, 4(1), 187221.

Mota, K. C. N. (2001) Marketing turístico: promovendo uma atividade sazonal. São Paulo: Atlas.

Pereira, V. (2001). Intenções estratégicas no planejamento urbano de Belo Horizonte: modernização espacial, internacionalização e city marketing (Tese de doutorado). Instituto de Pesquisa e Planejamento Urbano e Regional, Universidade Federal do Rio de Janeiro, Rio de Janeiro, RJ.

Pereira, R. M. F. A. (2003). Formação sócio-espacial do litoral de Santa Catarina (Brasil): gênese e transformações recentes. Geosul, 18(35), 99-129.

Poleza, M. M.; Butzke, L.; Rischbieter, I. K. (2008). Desenvolvimento territorial sustentável e turismo no Alto Vale do Itajaí, Santa Catarina: o associativismo municipal no projeto Tremtur. In Anais do IV Encontro Nacional da Associação Nacional de Pós-Graduação em Ambiente e Sociedade (pp. 1-17). Brasília, DF. 
Presidente Getúlio. (2016). Prefeitura Municipal. História da cidade. Recuperado de http://bit.ly/2qh0fsw

Presidente Nereu. (2015). Prefeitura Municipal. História da cidade. Recuperado de http://bit.ly/2qhlQ3V

Rost, C. A. (2008). A identidade do teuto-brasileiro na região sul do Brasil. Interdisciplinar, 5(5), 215-236.

Santos S.C. (2000). O Panorama sociodemográfico no início do século. In Corrêa, C. H. (Org.). A realidade catarinense no século XX (2ª ed., pp. 115-117). Florianópolis, SC: IHGSC.

Santos, M. (1982). Espaço e sociedade: ensaios (2ª ed.). Petrópolis, RJ: Vozes.

Silva, V. A. (2002). A formação do mercado socialmente elaborado nos sistemas de centros comerciais do Vale do Itajaí (Dissertação de mestrado). Programa de Pós-Graduação em Desenvolvimento Regional, Blumenau, SC.

Singer, P. (1984). Interpretação do Brasil: uma experiência histórica de desenvolvimento. In Fausto, B. História geral da civilização brasileira (v. 3, pp. 209-245). São Paulo, SP: Difel.

Vitor Meireles. (2014). Prefeitura Municipal. Histórico. Recuperado de http://bit.ly/2rip7V2

Witmarsum. (2016). Prefeitura Municipal. Apresentação. Recuperado de http://bit. ly/2rRhj9N

Recebido em: 02/07/2016

Aprovado em: 01/06/2017 